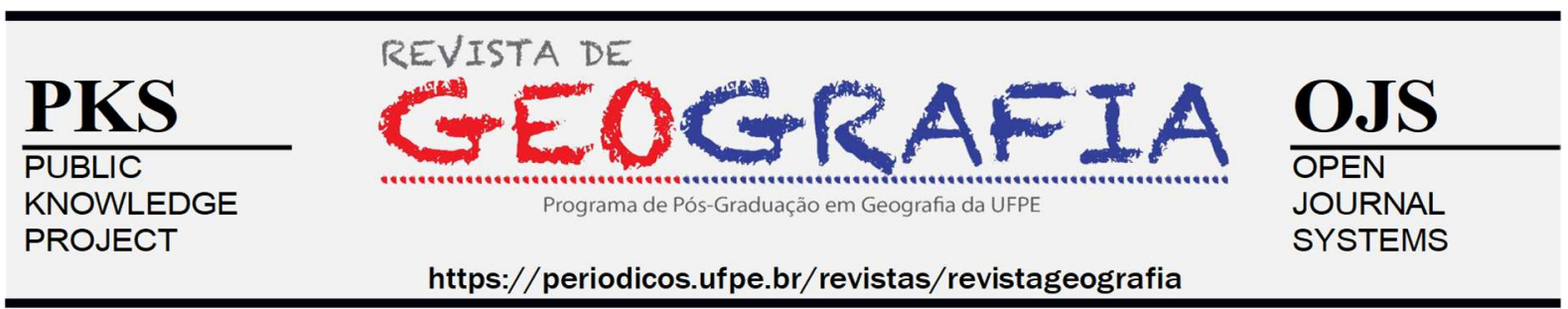

\title{
AVALIAÇÃO DE CONFLITOS PELA POSSE DE TERRAS EM SÃO FÉLIX DO XINGU - PARÁ: ABORDAGEM À LUZ DOS PRINCÍPIOS DE OSTROM E CENÁRIOS DE COBERTURA DO SOLO
}

\author{
Higor Costa de Brito ${ }^{1}$, Jessica Kaori Sasaki², Márcia Maria Rios Ribeiro ${ }^{3}$
}

\begin{abstract}
${ }^{1}$ Doutorando em Engenharia Civil e Ambiental pelo Programa de Pós Graduação em Engenharia Civil e Ambiental da Universidade Federal de Campina Grande. E-mail: h_igor@ hotmail.com. ORCID: https://orcid.org/0000-00034721-7197

2 Mestranda em Engenharia Civil e Ambiental pelo Programa de Pós Graduação em Engenharia Civil e Ambiental da Universidade Federal de Campina Grande. E-mail: jessicakaori@ hotmail.com. ORCID: https://orcid.org/00000003-1304-6297

${ }^{3}$ Professora Doutora do Programa de Pós Graduação em Engenharia Civil e Ambiental da Universidade Federal de Campina Grande. E-mail: mm-ribeiro@uol.com.br. ORCID: https://orcid.org/0000-0002-3446-6752
\end{abstract}

Artigo recebido em 05/07/2020 e aceito em 05/03/2021

\begin{abstract}
RESUMO
A posse da terra no Brasil envolve mecanismos incertos e controversos. Com intuito de subsidiar a análise e resolução de conflitos agrários, este estudo utiliza-se dos trabalhos de Ostrom (Princípios Institucionais) com o objetivo de verificar o sistema de governança do município de São Félix do Xingu, localizado na porção sul do estado do Pará, sinalizando potenciais danos ambientais através de técnicas baseadas na Teoria dos Jogos. Após a identificação e caracterização dos fatores mais relevantes no conflito ambiental, técnicas de sensoriamento remoto aliadas à Teoria dos Jogos foram utilizadas para modelagem de cenários de cobertura do solo na região. A análise dos princípios de Ostrom mostra que esses se encontram ausentes ou parcialmente presentes no caso estudado, uma vez que estão dispostos na legislação. Na prática, entretanto, há dificuldades na aplicação, no monitoramento e cumprimento. Avaliando os sistemas de governança, percebe-se que o arcabouço legal é bem estruturado, apresentando diversas leis e órgãos gestores. No entanto, existe uma falta de integração entre os órgãos públicos, que acarreta incompatibilidades na própria legislação. Os cenários de cobertura do solo modelados na pesquisa destacam a incompatibilidade dos resultados com o Plano Diretor Municipal e com o Código Florestal, onde limites privados regulamentados ferem as diretrizes legais estabelecidas.
\end{abstract}

Palavras-chave: conflitos agrários; Amazônia; governança; teoria dos jogos. sensoriamento remoto. 


\title{
EVALUATION OF CONFLICTS BY LAND OWNERSHIP IN SÃO FÉLIX DO XINGU - PA: APPROACH IN THE LIGHT OF THE OSTROM PRINCIPLES AND LAND COVER SCENARIOS
}

\begin{abstract}
Land ownership in Brazil involves uncertain and controversial mechanisms. In order to assist in the analysis and resolution of agrarian conflicts, this study uses the work of Ostrom (Institutional Principles) in order to analyze the governance system of the municipality of São Félix do Xingu, located in the southern portion of the state of Pará, signaling potential environmental damage through techniques based on Game Theory. After identifying and characterizing the most relevant factors in the environmental conflict, remote sensing techniques combined with Game Theory were used to model land cover scenarios in the region. The analysis of the principles of Ostrom shows that they are absent or partially present since they are laid down in the legislation. In practice, however, there are difficulties in application, monitoring, and enforcement. Evaluating the governance system, it is clear that the legal framework is well structured, presenting several laws and managing bodies. However, there is a lack of integration between public bodies, which results in incompatibilities in the legislation itself. The land cover scenarios modeled in the research highlight the incompatibility of the results with the Municipal Master Plan and the Forest Code, where regulated private limits violate the established legal guidelines.
\end{abstract}

Keywords: agrarian conflicts; Amazon; governance; game theory; remote sensing.

\section{EVALUACIÓN DE CONFLICTOS POR TENENCIA DE LA TIERRA EN SÃO FÉLIX DO XINGU - PA: ENFOQUE A LA LUZ DE LOS PRINCIPIOS DE OSTROM Y ESCENARIOS DE CUBIERTA DE TIERRAS}

\begin{abstract}
RESUMEN
La tenencia de la tierra en Brasil implica mecanismos inciertos y controvertidos. Para apoyar el análisis y resolución de conflictos agrarios, este estudio utiliza los trabajos de Ostrom (Principios Institucionales) para verificar el sistema de gobernanza del municipio de São Félix do Xingu, ubicado en la porción sur del estado de Pará, señalización de posibles daños ambientales mediante técnicas basadas en la teoría de juegos. Luego de identificar y caracterizar los factores más relevantes en el conflicto ambiental, se utilizaron técnicas de teledetección combinadas con la Teoría de Juegos para modelar escenarios de cobertura terrestre en la región. El análisis de los principios de Ostrom muestra que estos están ausentes o parcialmente presentes en el caso estudiado, tal y como están previstos en la legislación. En la práctica, sin embargo, existen dificultades en la aplicación, el seguimiento y el cumplimiento. Al evaluar los sistemas de gobernanza, se puede observar que el marco legal está bien estructurado, con varias leyes y órganos de gestión. Sin embargo, existe una falta de integración entre los organismos públicos, lo que genera incompatibilidades en la propia legislación. Los escenarios de cobertura del suelo modelados en la investigación resaltan la incompatibilidad de los resultados con el Plan Maestro Municipal y el Código Forestal, donde los límites privados regulados violan los lineamientos legales establecidos.
\end{abstract}

Palabras clave: conflictos agrarios. Amazonas. gobernancia. teoría de juego. detección remota. 


\section{INTRODUÇÃO}

A posse da terra no Brasil envolve mecanismos incertos e controversos. O território brasileiro concentra uma das maiores áreas aráveis do mundo, em contraponto, possui uma das taxas mais altas de concentração latifundiária e há casos de conflitos focados na terra, tanto em áreas urbanas quanto rurais (REYDON, 2019). Inúmeros conflitos foram exacerbados por mudanças na estrutura legal que regulam as áreas protegidas e o mercado de terras (SPAROVEK et al., 2019).

Na região norte do país, injustiças socioespaciais são confirmadas pela expansão dos conflitos fundiários envolvendo populações indígenas, quilombolas, posseiros, grileiros, desmatadores ilegais e sem-terra. O desenvolvimento na Amazônia, baseado na exploração dos recursos naturais e vivenciado a partir de 1970, acarretou num processo de apropriação fundiária e concentração de renda (ESCADA et al., 2005).

Medidas como incentivos fiscais foram oferecidas a grandes empresários e grupos econômicos para incentivar investimentos na região, principalmente em atividades como a mineração, agricultura, indústria e setores extrativos de madeira (LOUREIRO et al., 2005). Tais ações promoveram, significativamente, injustiças espaciais em termos de desenvolvimento geográfico desigual e desterritorialização de populações autóctones, evidenciando problemas de governança e padrões altamente desiguais de propriedade da terra (REYDON; FERNANDES; TELLES, 2015; SILVA; BAMPI, 2019).

O estado do Pará (PA) encontra-se inserido nesse contexto. Nessa região, a presença de diferentes atores e atividades econômicas influenciam a dinâmica territorial atual. O Estado vivencia a expansão ilegal da agropecuária nas regiões de preservação ambiental e áreas de demarcação indígena. O município de São Félix do Xingu, localizado na porção sul do Estado, apresentou, segundo o Sistema de Alerta do Desmatamento (SAD) elaborado pelo Imazon em 2019, a área de proteção ambiental mais desmatada do Brasil - APA Triunfo do Xingu, administrada pelo Estado (SAD, 2019).

A combinação de parâmetros biofísicos e sociais é um escopo importante para pesquisas direcionadas ao meio ambiente e sustentabilidade. Nesse aspecto, o presente trabalho tem como objetivo analisar o sistema de governança do município de São Félix do Xingu e sinalizar potenciais danos ambientais através de técnicas baseadas na Teoria dos Jogos. 


\section{GOVERNANÇA DOS RECURSOS DE USO COMUM}

O termo governança é utilizado em diversas áreas do conhecimento e apresenta inúmeros conceitos. No âmbito deste trabalho, o conceito de governança é entendido como um conceito normativo, onde as organizações governamentais devem trabalhar em conjunto com a sociedade e as partes interessadas, promovendo tomadas de decisão compartilhadas (SCHULZ et al., 2017). Nesse contexto, Tortajada (2010) enfatiza que para uma boa governança é necessária uma forte participação popular, consultas públicas, eficiência, transparência, ausência de corrupção, responsabilização, legitimidade, justiça e estado de direito, para que se possa obter, de fato, uma governança efetiva.

Em Governing the Commons, Ostrom (1990), contrapondo-se à teoria convencional dos bens comuns (HARDIN, 1968; OLSON, 2009), propôs uma abordagem que privilegia o uso sustentável dos recursos naturais de bem comum e aceita que, em certas condições, as comunidades possam se auto-organizar e estabelecer regras e instituições para uso sustentável dos recursos (TOTTI et al., 2013; PEREIRA et al., 2015).

Portanto, a autora apresenta um processo eficiente de gestão dos recursos de uso comum, onde o sucesso do governo depende da cooperação entre os atores envolvidos, que devem realizar esse processo de forma sustentável. (OSTROM, 1990; YI; FEIOCK, 2014; WITTMAN et al., 2017). Ostrom (1990) enumera um conjunto de princípios e de regras de propriedade coletiva que evitariam a sobre-exploração dos recursos. Uma vez que, os 8 princípios para governança dos recursos de uso comum (Quadro 1) estiverem presentes nos sistemas de governança, este apresentaria alta probabilidade de ser bem-sucedido, sendo, portanto, uma situação de caráter probabilístico (SEWARD et al., 2019; WAMSLER; RAGGERS, 2018; WANG et al., 2019). 
Quadro 1 - Princípios Institucionais estabelecidos por Ostrom (1990)

\begin{tabular}{|c|c|}
\hline Princípios de design & Justificativa \\
\hline 1. Limites claramente definidos & $\begin{array}{l}\text { Indivíduos ou famílias que têm direito de usar as unidades de recursos em } \\
\text { comum devem ser claramente definidos, assim como os limites do recurso } \\
\text { de uso comum devem ser definidos. }\end{array}$ \\
\hline $\begin{array}{l}\text { 2. Coerência entre as regras de } \\
\text { apropriação e de provisão com as } \\
\text { condições locais }\end{array}$ & $\begin{array}{l}\text { Regras de apropriação, restringindo tempo, lugar, tecnologia e/ou } \\
\text { quantidade de unidades de recursos, relacionam-se às condições locais e } \\
\text { às provisões de regras. }\end{array}$ \\
\hline $\begin{array}{l}\text { 3. Arranjos coletivos para as escolhas e } \\
\text { decisões }\end{array}$ & $\begin{array}{l}\text { As pessoas afetadas pelas regras operacionais devem participar das } \\
\text { decisões para modificações de tais regras. }\end{array}$ \\
\hline 4. Monitoramento & $\begin{array}{l}\text { Deve haver monitoramento das condições de uso do recurso de uso comum } \\
\text { e do comportamento do usuário. }\end{array}$ \\
\hline 5. Sanções graduais à transgressão & $\begin{array}{l}\text { Apropriadores que violam as regras devem ser avaliados por sanções } \\
\text { graduais por outros apropriadores, por funcionários responsáveis perante } \\
\text { estes apropriadores, ou por ambos. }\end{array}$ \\
\hline 6. Mecanismos de resolução de conflitos & $\begin{array}{l}\text { Apropriadores e seus funcionários têm acesso rápido e espaços de baixo } \\
\text { custo para resolver os conflitos entre os apropriadores ou entre os } \\
\text { apropriadores e seus funcionários. }\end{array}$ \\
\hline $\begin{array}{l}\text { 7. Reconhecimento mínimo de direitos } \\
\text { de organização }\end{array}$ & $\begin{array}{l}\text { Os direitos dos apropriadores para elaborar suas próprias instituições não } \\
\text { são contestados por autoridades governamentais externas. }\end{array}$ \\
\hline $\begin{array}{l}\text { 8. Aninhamento de instituições em rede } \\
\text { estruturada para articulação intersetorial } \\
\text { na gestão }\end{array}$ & $\begin{array}{l}\text { Para recursos que fazem parte de grandes sistemas, atividades de } \\
\text { apropriação, provisão, monitoramento, fiscalização, resolução de conflitos } \\
\text { e governança são organizadas em várias camadas de empreendimentos } \\
\text { aninhados. }\end{array}$ \\
\hline
\end{tabular}

Fonte: Adaptado de Ostrom (1990).

\section{SISTEMA SOCIOECOLÓGICO}

Dando sequência aos seus estudos, Ostrom (2007) propôs uma estruturação para analisar os sistemas socioecológicos complexos. Neste trabalho, para facilitar a identificação ao longo do texto, as variáveis do Sistema Socioecológico (SSE) foram associadas a siglas. A estruturação desse sistema permite que os pesquisadores organizem como os atributos dos Sistemas de Recursos (SR), as Unidades de Recursos (UR), os Atores (AT) e os Sistemas de Governança (SG) afetam conjuntamente e são indiretamente afetados pelas Interações (IN) e Resultados (RE) alcançados em um determinado momento e local (OSTROM, 2009; 2007).

No estudo de McGinnis e Ostrom (2014), os autores apresentam modificações nessa estrutura. A nova organização visou oferecer um rearranjo da lista de atributos relevantes dos SG e discutir outras maneiras de tornar essa estrutura aplicável a configurações de caráter político, além das configurações de recursos naturais. Sendo assim, o reconhecimento das variáveis que compõem o sistema torna-se útil para projetos de instrumentos de coleta de dados, 
na condução de trabalhos de campo e na análise de descobertas sobre a sustentabilidade de um SSE complexo (OSTROM, 2009).

A partir dessa estruturação, é possível compreender a influência das políticas no aumento da sustentabilidade em diferentes SR, o que possibilita o redirecionamento de futuras decisões através de modelagens conceituais ou numéricas (SHARMA et al., 2016; OSTROM, 2009).

\section{TEORIA DOS JOGOS E REGRA DA CHEGADA ALEATÓRIA}

A teoria dos jogos é uma teoria difundida no campo da matemática, que tem como objetivo modelar fenômenos que podem ser observados quando dois ou mais "agentes de decisão" interagem entre si. Essas modelagens fornecem resultados para a descrição de

processos de decisão conscientes e objetivos, envolvendo diversos indivíduos (MORGENSTERN; VON NEUMANN, 1944; SMITH, 1982).

Os "teóricos dos jogos" buscam entender o conflito e a cooperação, por meio de modelos quantitativos e exemplos hipotéticos (CAMERER, 2011). A partir de estudos anteriores (EPSTEIN, 1983; RABINOVITCH, 1971), O’Neill (1982) propôs uma forma alternativa para modelar resoluções de conflitos, denominada de Regra da Chegada Aleatória (RCA) - tradução do termo inglês Random Arrival Rule. Esse modelo é caracterizado pela arbitragem de interesses, na qual não existem regras preexistentes e os julgamentos são feitos sobre os interesses das partes, onde os indivíduos têm direitos sobrepostos a um bem transferível limitado.

A RCA é uma regra de alocação em que cada ator recebe a média que ele pode obter (ou seja, o mínimo da quantia igual à sua reivindicação e o que lhe resta por vez), se todos os requerentes aparecerem um por um de forma aleatória. Isso significa que a RCA é uma regra de alocação em que cada requerente recebe a "expectativa" de suas compensações marginais. A RCA é indicada para compreender conflitos onde as reclamações estão relacionadas à situação em que há um grupo de reclamantes exigindo um recurso, mas o valor a ser dividido não é suficiente para atender a todas as reclamações (CHUN; LEE, 2007). Dessa forma, essa regra de alocação torna-se adequada para analisar o conflito em questão. 


\section{METODOLOGIA}

\section{São Félix do Xingu: características territoriais e conflitos pela terra}

Esta pesquisa teve como área de estudo o município de São Félix do Xingu (Figura 1), localizado ao sul do estado do Pará. O município compreende uma área de aproximadamente $85.000 \mathrm{~km}^{2}$, com uma população estimada em 124.806 habitantes (IBGE, 2019). A região está inserida no bioma Amazônia, possui demarcações de terras indígenas (FUNAI, 2019) e quatro unidades de conservação administradas pelo governo federal (ICMBIO, 2019). A economia do município é caracterizada pela pecuária de corte, produção agrícola e mineração industrial, com um grande rebanho bovino e lavouras permanentes (SCHMINK et al., 2019).

O município é palco de diversos conflitos entre trabalhadores rurais, indígenas, grandes latifundiários e membros do Movimento dos Trabalhadores Rurais Sem Terra (MST). Nesta região, o conflito vai além de um embate por terra, pois está relacionado às demandas externas, diretamente afetadas por dinâmicas internacionais, acarretando migrações desordenadas e na urbanização sem serviços públicos de qualidade (PALHETA et al., 2017).

Figura 1 - Localização e demarcações de terras do município de São Félix do Xingu

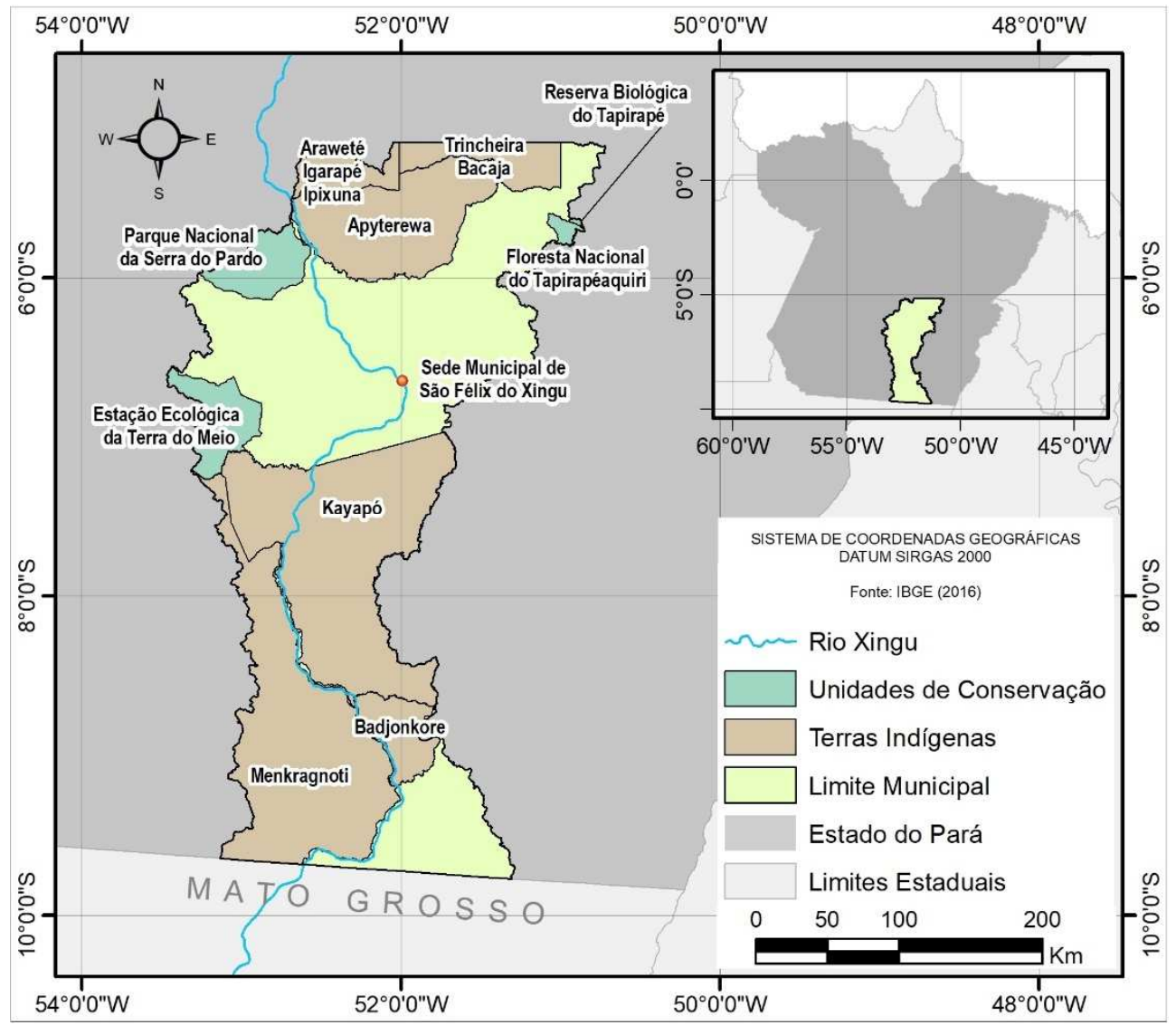

Fonte: Elaboração própria. 


\section{Análise dos princípios de Ostrom e do Sistema SSE em São Félix do Xingu}

Para a verificação da presença dos princípios de Ostrom (1990), no contexto de conflitos agrários no município estudado, realizou-se levantamento bibliográfico sobre os estudos de Ostrom a respeito da Governança de Recursos de Uso Comum (Common-Pool Resources) (OSTROM, 1990; 2009; 2007; MCGINNIS; OSTROM, 2014). Em seguida, desenvolveu-se o estudo sobre o município referente à situação no ano de 2018 dos conflitos agrários, bem como sobre o arcabouço legal em relação à preservação da floresta amazônica e demarcação de áreas indígenas (MARTINEZ et al., 2007; SOARES-FILHO et al., 2005). Posteriormente, construiu-se um quadro que analisa a existência dos oito princípios na região de estudo, classificando-os como presente, parcialmente presente ou ausente.

Com relação a estruturação do SSE, foi analisado o conflito ambiental presente na região, onde foi possível definir as variáveis de nível superior. Em relação ao SR, identificouse a região da Floresta Amazônica pertencente ao município, tendo como UR a área desmatada da floresta (em quilômetros quadrados), sendo essa unidade pertencente ao SR como um todo. Com referência aos AT sociais envolvidos no conflito, apresentam-se: os agropecuaristas, que objetivam a expansão de suas terras; os povos indígenas, que buscam continuar com suas práticas tradicionais na região; o governo, que busca conciliar os interesses dos envolvidos, além de garantir o cumprimento e fiscalização das leis vigentes. Quanto aos SG que definem regras para os AT, foram identificadas: a Lei Federal n 12.651 de 2012 (Código Florestal), a Lei Federal no 10.257 de 2001 (Estatuto das cidades) e a Lei Municipal n 320 de 2006 (Plano Diretor Municipal).

Após a identificação das variáveis de primeiro nível, foi possível reconhecer as variáveis de segundo nível (subvariáveis), consideradas variáveis de nível mais profundo, capazes de detalhar cada subsistema (OSTROM, 2009). As subvariáveis foram identificadas a partir da análise do contexto social, econômico e político do município em estudo, com base em Escada et al. (2005) e Martinez et al. (2007). Em relação ao cenário, o sistema estudado é de caráter econômico, levando em consideração a subvariável de desenvolvimento econômico. Nos SR, foram identificados quatro subcomponentes. Essas variáveis se relacionam com o setor que o recurso se encontra, o seu tamanho e quanto à previsibilidade do sistema, relacionando o conhecimento sobre o sistema e como ele reage a certos cenários.

Nos SG, foram identificadas oito subvariáveis correspondentes às Organizações Governamentais e Não Governamentais. No município não existe ONGs específicas para preservação da Amazônia, mas existem ONGs de âmbito geral, atuando na Amazônia como um 
todo, como por exemplo o IPAM - Instituto de Pesquisa Ambiental da Amazônia, AVIVE Associação Vida Verde da Amazônia, FAS - Fundação Amazonas Sustentável, IMAZON, entre outras (CARNEIRO, 2007; ALMEIDA et al., 2018). Também foram levadas em consideração regras de monitoramento e sancionamento que encontram-se presentes na Lei $\mathrm{n}^{\circ}$ 12.651 de 2012, que estabelece o Cadastro Ambiental Rural (CAR) no âmbito do Sistema Nacional de Informação sobre Meio Ambiente (SINIMA), como forma de monitoramento, bem como a Lei no 9.605 de 1998 (Lei de Crimes Ambientais), que estabelece as sanções.

Em relação às UR, foram observadas cinco variáveis que caracterizam o recurso, capazes de especificar a mobilidade da unidade, a taxa de crescimento ou substituição, o valor econômico, entre outras características. Com relação aos AT, observaram-se componentes que se relacionam com o número de AT relevantes, os atributos socioeconômicos destes, o histórico e vivências passadas, além da importância do recurso para cada usuário, bem como a relação de reciprocidade e confiança que existem entre os envolvidos. Com relação às Situações de Ação Focal (SA), buscou-se analisar quais variáveis se adequam ao problema em estudo, relacionando as IN e os RE advindos destas.

\section{Construção de cenários}

As informações referentes as mudanças da cobertura da terra foram extraídas da versão 3.1 do Mapeamento Anual da Cobertura e Uso do Solo do Brasil (MapBiomas), proposto por Souza e Azevedo (2017), por meio da plataforma Google Earth Engine. Essa etapa teve como objetivo identificar o avanço de atividades agropecuárias no município. Para avaliar esse avanço, três classificações de cobertura do solo (pastagem, agricultura e mosaico de agricultura e pastagem) foram agregadas e posteriormente quantificadas com o auxílio da linguagem de programação R (TEAM, 2013), gerando a classificação denominada “atividade agropecuária".

A quantificação gerou resultados com base no número de células (pixels) presentes no mapeamento para o limite do município. O MapBiomas possui resolução espacial de 30 metros, dessa forma, os resultados foram convertidos em unidades de área (quilômetros quadrados) e usados como dados de entrada para o modelo da RCA (O’NEILL, 1982).

Para a aplicação da regra, foi pressuposto que os envolvidos atuantes em áreas nativas protegidas (terras indígenas e unidades de conservação federais) reivindicam apenas sua área atual. Vale salientar que o termo "área atual" refere-se à classificação do ano de 2017 do MapBiomas, ou seja, as áreas demarcadas por lei subtraídas da porção que já foi invadida. Por outro lado, a reivindicação dos agropecuaristas foi analisada em duas abordagens: (i) os 
agropecuaristas reivindicam, além da sua área atual, a área correspondente às terras indígenas; (ii) os agropecuaristas reivindicam todas as áreas de preservação.

A RCA foi modelada na linguagem de programação R, através da função Random Arrival, integrante do pacote GameTheory (CANO-BERLANGA et al., 2017). Objetivando a simplificação da análise e explanação dos resultados obtidos, foram construídos quatro cenários de ocupação do município, conforme ilustrado na Figura 2. Vale destacar que apenas o Cenário 1 está de acordo com as demarcações presentes nas leis vigentes, entretanto, com a constante expansão agropecuária na região, torna-se utópica a elaboração de cenários em que haja crescimento de áreas de preservação (SILVA et al., 2019).

Figura 2 - Cenários elaborados a partir das análises realizadas.
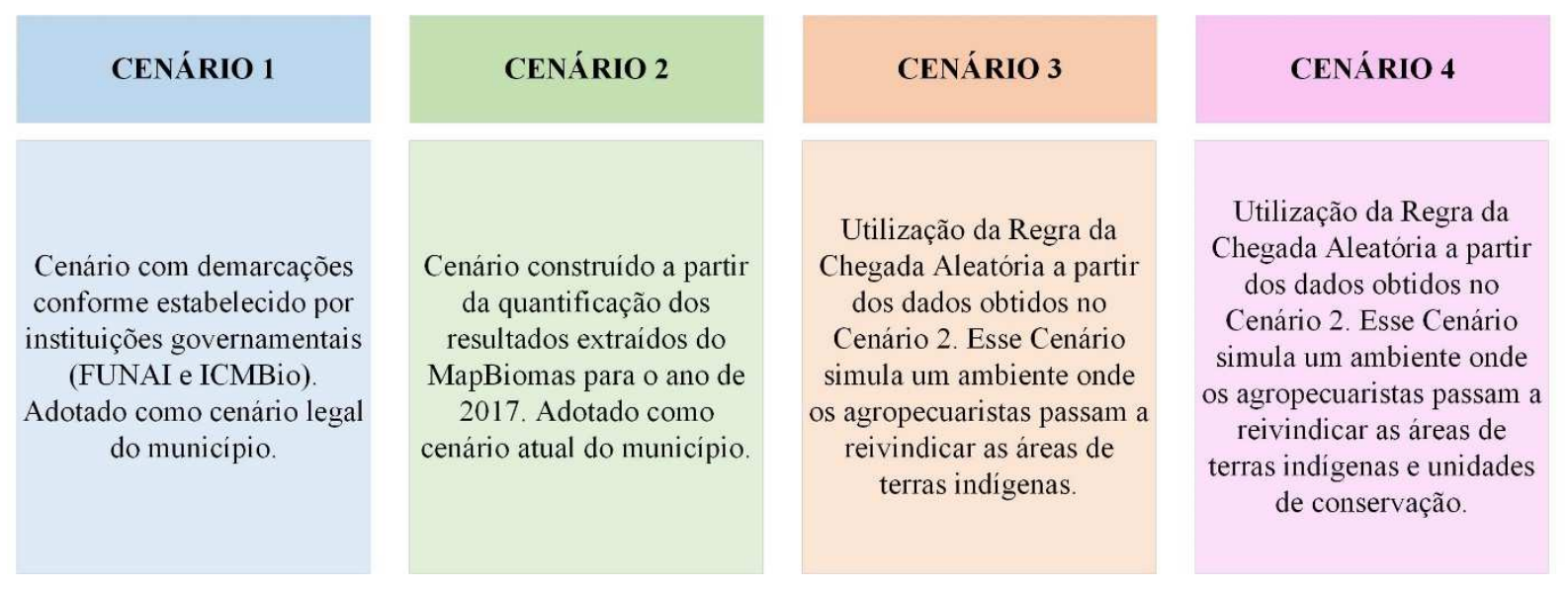

Fonte: Elaboração própria.

\section{RESULTADOS E DISCUSSÃO}

Em relação aos princípios de Governança de Ostrom (OSTROM, 1990) no contexto do conflito estudado, constatou-se que para o Princípio 1 os limites estão bem definidos através de demarcações de área rural encontradas na plataforma do CAR (onde questões ligadas a legalização de propriedades continuam sendo um problema em áreas fronteiriças), das áreas de preservação ambiental demarcadas e registradas no site do ICMBio (Instituto Chico Mendes) e das áreas indígenas demarcadas e registradas no site da FUNAI. Há, entretanto, inconsistências referentes às delimitações municipais.

O Princípio 2 apresenta-se parcialmente presente na área de estudo, pois percebe-se que existem divergências entre as legislações de âmbito federal e municipal, relacionadas principalmente a delimitação do zoneamento ecológico econômico. O Princípio 3 foi considerado ausente, uma vez que não existe a participação ativa da sociedade na tomada de decisões para modificação das regras em vigor. 
Os Princípios 4 e 5 foram constatados nas leis vigentes, porém, na prática, não existe o efetivo cumprimento desses, sendo enquadrado como ausentes. O Princípio 6 também foi considerado ausente, pois, mesmo diante da Resolução de $n^{\circ} 10$, de 17 de outubro de 2018, os conflitos na região carecem de mecanismos efetivos para arbitrar os interesses dos envolvidos. O Princípio 7 classificou-se como sendo presente, pois o governo não possui a obrigação e nem deve interferir na criação de lideranças locais como sindicatos e associações. Cabe ao governo atuar no estímulo a formação dessas associações, pois em determinados casos, o posicionamento dessas organizações pode causar danos as suas verdadeiras funções. Por fim, o Princípio 8 foi considerado parcialmente presente, uma vez que, apesar dos órgãos gestores serem bem estruturados, existe falta de integração entre eles. Os princípios, suas verificações e motivações, que acarretaram as classificações supracitadas, encontram-se ilustrados de forma simplificada no Quadro 2.

Quadro 2 - Verificação da presença dos princípios de Ostrom no Município

\begin{tabular}{|c|c|c|}
\hline Princípios de Ostrom & $\begin{array}{l}\text { Princípio } \\
\text { identificado na área } \\
\text { de estudo? }\end{array}$ & Motivo \\
\hline 1. Limites claramente definidos & Parcialmente & $\begin{array}{c}\text { Os limites estão bem definidos em órgãos federais, } \\
\text { entretanto, há inconsistências quando comparados a } \\
\text { delimitações municipais }\end{array}$ \\
\hline $\begin{array}{l}\text { 2. Congruência entre apropriação } \\
\text { e provisão de regras e condições } \\
\text { locais }\end{array}$ & Parcialmente & $\begin{array}{l}\text { Existem divergências entre as legislações de âmbito federal } \\
\text { e municipal, relacionadas principalmente a delimitação do } \\
\text { zoneamento ecológico econômico }\end{array}$ \\
\hline 3. Arranjos de escolhas coletivas & Não & $\begin{array}{c}\text { Não foi identificada uma participação ativa da sociedade } \\
\text { na tomada de decisões para modificação das regras em } \\
\text { vigor }\end{array}$ \\
\hline 4. Monitoramento & Parcialmente & \multirow{2}{*}{$\begin{array}{c}\text { Constatados nas leis vigentes, entretanto, não foram } \\
\text { identificados registros que comprovem um cumprimento } \\
\text { efetivo }\end{array}$} \\
\hline 5. Sanções Graduais & Parcialmente & \\
\hline $\begin{array}{l}\text { 6. Mecanismos de resolução de } \\
\text { conflitos }\end{array}$ & Parcialmente & $\begin{array}{l}\text { Mesmo diante da Resolução de } n^{\circ} 10 \text {, de } 17 \text { de outubro de } \\
2018 \text {, os conflitos na região carecem de mecanismos } \\
\text { efetivos para arbitrar os interesses dos envolvidos }\end{array}$ \\
\hline $\begin{array}{l}\text { 7. Reconhecimento mínimo de } \\
\text { direitos para se organizar }\end{array}$ & Parcialmente & $\begin{array}{l}\text { Não foram identificados indícios de que o governo } \\
\text { interfere na criação de lideranças locais como sindicatos e } \\
\text { associações }\end{array}$ \\
\hline 8. Empreendimentos aninhados & Parcialmente & $\begin{array}{l}\text { Apesar dos órgãos gestores serem bem estruturados, foi } \\
\text { constatada a falta de integração entre eles }\end{array}$ \\
\hline
\end{tabular}

Fonte: Elaboração própria.

Nota-se que a maioria dos princípios encontram-se ausentes ou parcialmente presente, uma vez que tais princípios estão presentes na legislação, que é bem definida e estruturada. $\mathrm{Na}$ 
prática, porém, há dificuldades na implementação, no monitoramento e no cumprimento dessas leis. Nesse contexto, as variáveis e subvariáveis do SSE foram identificadas e estruturadas, conforme apresentado no Quadro 3. Essa estruturação influenciou diretamente a ausência de sustentabilidade do SSE (Figura 3). Os resultados advindos dessas interações, ou a falta destas, é de importância para compreender o comportamento do sistema em cenários distintos.

Quadro 3 - Variáveis de primeiro e segundo níveis do Sistema Socioecológico

\begin{tabular}{|c|c|}
\hline Variável de primeiro nível & Variáveis de segundo nível \\
\hline $\begin{array}{c}\text { Sistemas sociais, econômicos e } \\
\text { políticos relacionados (SS) }\end{array}$ & SS1 - Desenvolvimento econômico \\
\hline Sistemas de Recursos (SR) & $\begin{array}{c}\text { SR1 - Setor = Terras do município de São Félix do Xingu - PA } \\
\text { SR2 - Clareza dos limites do sistema = Existem divergências quanto a definição dos } \\
\text { limites } \\
\text { SR3 - Tamanho dos sistemas de recursos = Área total } \\
\text { SR4 - Instalações construídas pelo homem = Sim } \\
\text { SR7 - Previsibilidade da dinâmica do sistema = Previsível }\end{array}$ \\
\hline Sistemas de Governança (SG) & $\begin{array}{l}\text { SG1 - Organizações governamentais- Código Florestal- Lei no } 12651 \text { de } 2012 \text {; } \\
\text { Estatuto das cidades - Lei no } 10257 \text { de } 2001 \text {; Plano Diretor Municipal - Lei n }{ }^{\circ} \\
320 / 2006 \\
\text { SG2 - Organizações não governamentais- Não existe ONGs específicas no município, } \\
\text { mas existem ONGs da Amazônia como um todo (ex. AMPA, AVIVE, FAZ, } \\
\text { IMAZON, etc.) } \\
\text { SG3 - Estrutura de rede = Hierarquizada } \\
\text { SG4 - Sistemas de direitos de propriedade = Plano Diretor Municipal } \\
\text { SG6 - Regras de escolha coletiva = Advém do Plano Diretor } \\
\text { SG7 - Regras de escolha constitucional = Presente (legislação) } \\
\text { SG8 - Regras de monitoramento e sancionamento = CAR - Lei n }{ }^{\circ} 12651 \text { de 2012; Lei } \\
\text { de crimes ambientais - Lei }{ }^{\circ} \text { 9.605 de } 1998\end{array}$ \\
\hline Unidades de Recursos (UR) & $\begin{array}{c}\text { UR1 - Mobilidade das unidades de recursos = Inexistente } \\
\text { UR2 - Taxa de crescimento ou substituição = Baixa } \\
\text { UR4 - Valor econômico = Alto } \\
\text { UR6 - Características distintivas = Tipo de cobertura do solo } \\
\text { UR7 - Distribuição espacial e temporal = Município de São Félix do Xingu período de } \\
2017\end{array}$ \\
\hline Atores (AT) & $\begin{array}{c}\text { AT1 - Número de atores relevantes = } 3 \text { atores } \\
\text { AT2 - Atributos socioeconômicos = Alta variação } \\
\text { AT3 - História ou experiências passadas = Histórico de ocupação do solo (1985 -2017) } \\
\text { AT5 - Liderança / empreendedorismo = Existe algum tipo de organização, } \\
\text { apresentando líderes. } \\
\text { AT6 - Normas (confiança-reciprocidade) / capital social = Baixo } \\
\text { AT8 - Importância do recurso (dependência) = Alta }\end{array}$ \\
\hline $\begin{array}{l}\text { Situações de ação: Interações } \\
\quad(\text { IN) } \rightarrow \text { Resultado (RE) }\end{array}$ & $\begin{array}{c}\text { IN1 - Colheita } \\
\text { IN7 - Atividades auto-organizadas } \\
\text { IN8 - Atividades de Networking } \\
\text { IN9 - Atividades de monitoramento } \\
\text { RE2 - Medidas de desempenho ecológico }\end{array}$ \\
\hline $\begin{array}{l}\text { Ecossistemas Relacionados } \\
\text { (ECO) }\end{array}$ & $\begin{array}{c}\text { ECO1 - Padrões climáticos } \\
\text { ECO2 - Padrões de poluição } \\
\text { ECO3 - Flui para dentro e fora do SSE focal }\end{array}$ \\
\hline
\end{tabular}

Fonte: Elaboração própria com base em McGinnis e Ostrom (2014). 
Figura 3 - Sistema Socioecológico estudado

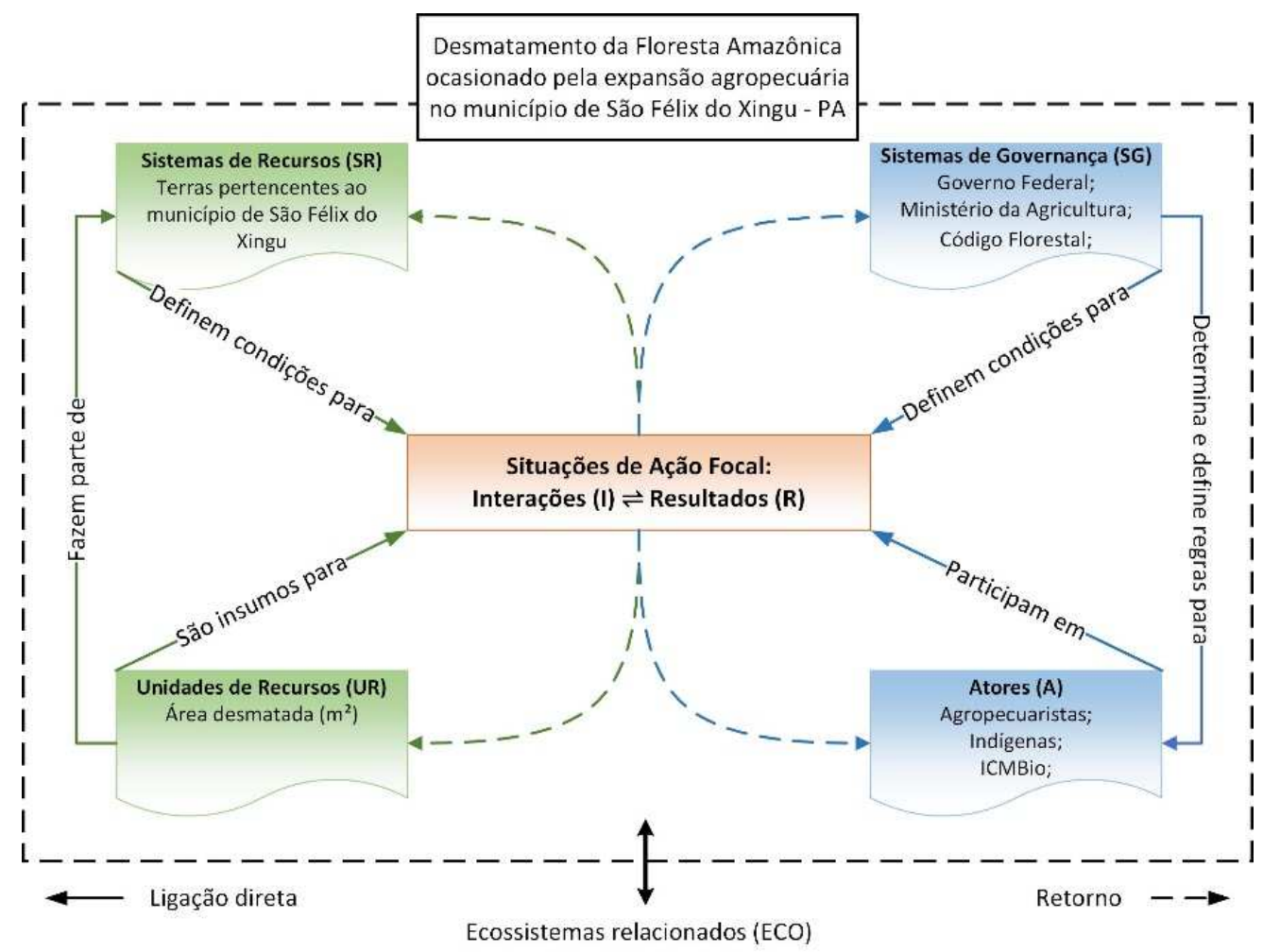

Fonte: Elaboração própria com base em McGinnis e Ostrom (2014).

A partir da análise do SSE e das variáveis de segundo nível, observou-se no sistema de AT que o histórico do município tem forte influência na ocupação das terras atuais. A colonização do município foi baseada na exploração dos recursos naturais, entre 1980 e 1990 houve um aumento do fluxo migratório acompanhado do processo de concentração fundiária pelos grandes agropecuaristas (AMARAL et al., 2006), que se consolida atualmente. Portanto, o histórico do município reflete os conflitos entre os AT, no qual um dos envolvidos deseja expandir desenfreadamente suas áreas, visando a compensação financeira e gerando, assim, uma falta de confiança e reciprocidade entre os envolvidos no sistema.

Avaliando os SG, percebe-se que o arcabouço legal é bem estruturado e apresenta diversas leis e órgãos gestores não só para o município estudado, mas na Amazônia como um todo, entretanto faz-se necessário uma política clara, com foco e objetivos bem definidos que favoreça o desenvolvimento econômico aliado a estratégias de conservação. A falta de compatibilidade entre órgãos governamentais, juntamente com a ineficácia da fiscalização para o cumprimento das leis corroboram com a insuficiência de sustentabilidade do sistema, agravando os conflitos pela posse de terras (SCHMITT, 2015). Nos SR e nas UR, devido à baixa taxa de substituição do recurso, há um alto valor econômico relacionado. Além disso, a extração do recurso para expansão agropecuária gera grandes lucros, sendo o maior responsável 
pela economia do município em estudo, fator que aumenta ainda mais seu valor econômico (AMARAL et al., 2006). Fatos como esse corroboram um dos principais problemas enfrentados na Amazônia: a clareza dos limites e a fragilidade do direito de propriedade (DINIZ et al., 2009; FEISTAUER et al., 2014).

Sobre as SA, identificou-se que o desmatamento descontrolado ocasiona degradação ambiental e que, caso existisse uma auto-organização, juntamente com atividades integradas e monitoramento efetivo da expansão agropecuária, seria possível obter como resultado a conservação da Floresta Amazônica e por consequência o uso sustentável do recurso.

Em relação aos efeitos do desmatamento nesse tipo de ecossistema, destacam-se as mudanças climáticas, que afetam diretamente os níveis de evapotranspiração e aumenta a temperatura do ambiente. Essa variação torna o clima mais seco e diminui os índices pluviométricos, podendo influenciar o clima de regiões distantes da própria Amazônia (MARENGO et al., 2011). Nesse contexto, vale ressaltar os problemas relacionados a perdas de espécies de plantas e animais, além da poluição atmosférica ocasionada pela extração ilegal da madeira através das queimadas (FONSECA-MORELLO et al., 2017).

As discussões abordadas na aplicação dos Princípios de Ostrom e na construção do SSE serviram de base para definição dos atores e compreensão dos conflitos da região, onde aliados aos dados obtidos por sensoriamento remoto, foi possível construir e quantificar cenários de cobertura do solo. O resultado gerado a partir dos produtos MapBiomas foi a análise do avanço das atividades agropecuárias do município de São Félix do Xingu para os anos de 1985, 2000 e 2017 (Figura 4), com base no resultado, é possível constatar o avanço de atividades agropecuárias em áreas nativas protegidas, além de retratar uma degradação acentuada nas áreas remanescentes, onde grande parte deveria ser destinada à Reserva Legal. 
Figura 4 - Cobertura do solo do município de São Félix do Xingu

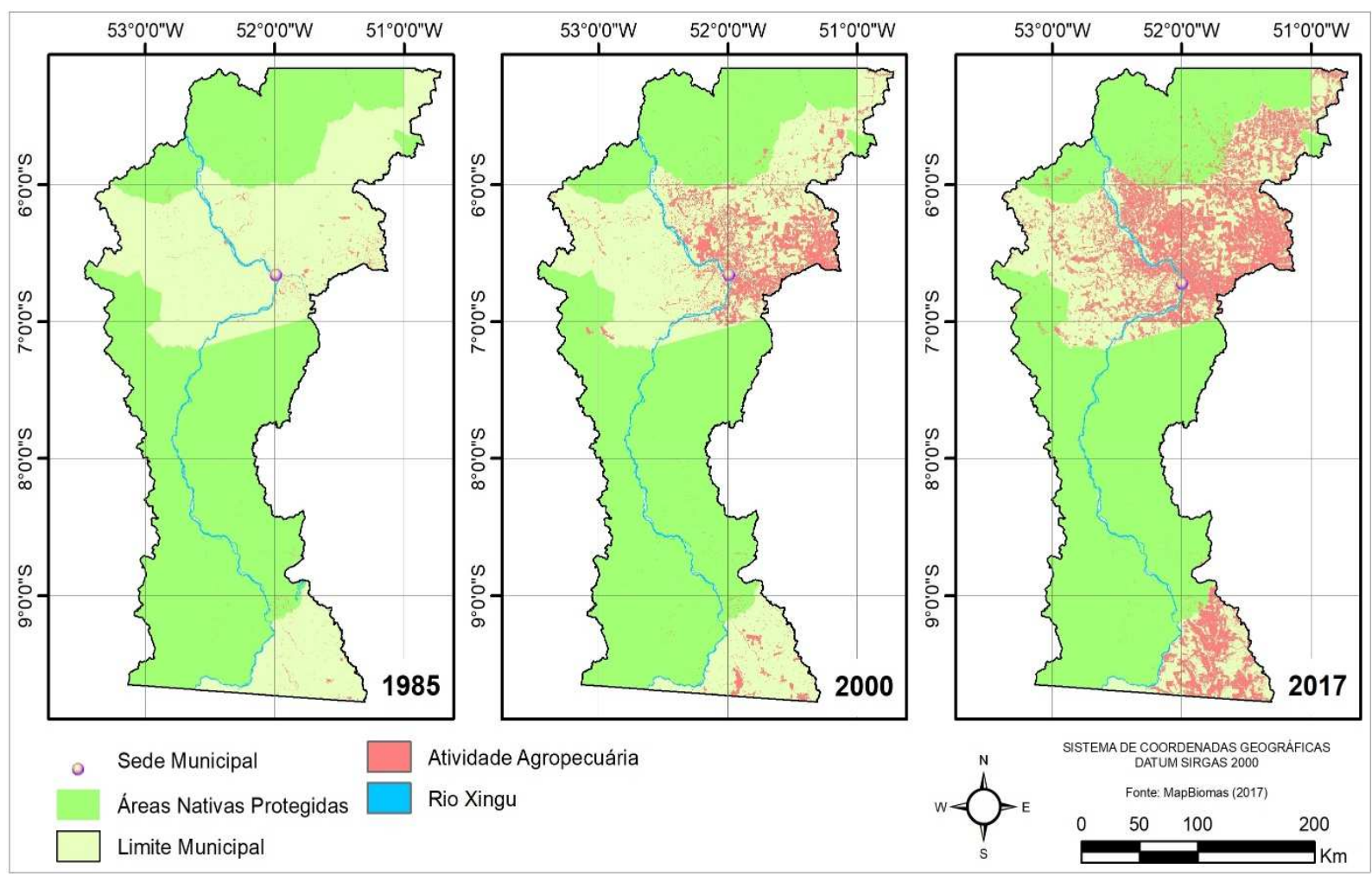

Fonte: Adaptado de MapBiomas (2017).

Após a quantificação dos mapas de classificação de cobertura do solo, os cenários propostos foram formulados (Figura 5). O Cenário 1 pode ser configurado como o cenário ideal, onde todas as delimitações propostas pelos órgãos governamentais são obedecidas, não apresentando nenhuma área nativa protegida degradada por atividades agropecuárias ou área agrícola irregular (área de reserva legal com atividade agrícola). Esse cenário indica que 59\% do território é destinado a áreas de terras indígenas e unidades de conservação federais, ou seja, ao considerar as áreas de reservas legais, o município deve apresentar 77\% de sua cobertura (aproximadamente $65.994,29 \mathrm{~km}^{2}$ ) composta por áreas vegetadas preservadas.

O Cenário 2 retrata o cenário mais próximo do atual, construído a partir dos dados do MapBiomas para o ano de 2017. O cenário aponta que 448,68 km² de áreas de preservação foram degradadas por atividades agropecuárias, além de constatar a antropização de 2.415,06 $\mathrm{km}^{2}$ em áreas de Reserva Legal. Tais resultados indicam que cerca de 4\% $\left(2.863,64 \mathrm{~km}^{2}\right)$ do território está ocupado de forma ilegal, desrespeitando as delimitações determinadas pelo governo federal (BRASIL, 2012). 
Figura 5 - Cenários configurados pelas delimitações governamentais e situação atual

\begin{tabular}{|c|c|c|c|c|c|c|}
\hline \multirow{2}{*}{$\begin{array}{c}\text { Classificação da } \\
\text { Área }\end{array}$} & \multicolumn{3}{|c|}{ Cenário 1 (Legal) } & \multicolumn{3}{|c|}{ Cenário 2 (Atual - Classificação 2017 do MapBiomas) } \\
\hline & Descrição & Área $\left(\mathrm{km}^{2}\right)$ & Área (\%) & Descrição & Área $\left(\mathrm{km}^{2}\right)$ & Área (\%) \\
\hline TI: Terras Indigenas & $\begin{array}{l}\text { Totalmente } \\
\text { Preservadas }\end{array}$ & 45539.57 & $53 \%$ & $\begin{array}{l}\text { Parcialmente } \\
\text { Preservadas }\end{array}$ & 45201.81 & $53 \%$ \\
\hline $\begin{array}{l}\text { UCs: Unidades de } \\
\text { Conservação Federais }\end{array}$ & $\begin{array}{l}\text { Totalmente } \\
\text { Preservadas }\end{array}$ & 5135.04 & $6 \%$ & $\begin{array}{l}\text { Parcialmente } \\
\text { Preservadas }\end{array}$ & 5024.11 & $6 \%$ \\
\hline $\begin{array}{c}\text { CAR: Áreas de Cadastro } \\
\text { Ambiental Rural }\end{array}$ & Totalmente Utilizada & 30614.49 & $36 \%$ & Totalmente Utilizada & 30614.49 & $36 \%$ \\
\hline $\begin{array}{c}\text { ARL: Área de Reserva } \\
\text { Legal (Dentro das Áreas } \\
\text { de CAR) }\end{array}$ & Totalmente Preservada & 15319.68 & $18 \%$ & $\begin{array}{l}\text { Parcialmente } \\
\text { Preservada }\end{array}$ & 12904.62 & $15 \%$ \\
\hline $\begin{array}{c}\text { AND: Áreas Protegidas } \\
\text { Degradadas }\end{array}$ & $\begin{array}{l}\text { Nenhuma Área } \\
\text { Degradada }\end{array}$ & 0.00 & $0 \%$ & Invasões Pontuais & 448.68 & $1 \%$ \\
\hline $\begin{array}{c}\text { AR: Áreas } \\
\text { Remanescentes (Area } \\
\text { Total - TI - UCS - CAR) }\end{array}$ & Sem Alterações & 4025.13 & $5 \%$ & Sem Alterações & 4473.82 & $5 \%$ \\
\hline $\begin{array}{l}\text { AA: Área Agrícola } \\
\text { Irregular }\end{array}$ & $\begin{array}{l}\text { Áreas de Reserva Legal } \\
\text { Totalmente Preservada }\end{array}$ & 0.00 & $0 \%$ & $\begin{array}{l}\text { Áreas de Reserva Legal } \\
\text { com Produção Agrícola }\end{array}$ & 2415.06 & $3 \%$ \\
\hline
\end{tabular}

Fonte: Elaboração própria.

O cenário atual evidencia a fragilidade das terras indígenas na Amazônia Legal, as quais, como no restante do país, são extremamente vulneráveis, invadidas constantemente por madeireiros, garimpeiros, peixeiros, rizicultores, fazendeiros, posseiros, biopiratas e outros exploradores em busca do lucro fácil (HECK; LOEBENS; CARVALHO, 2005). No município de São Félix do Xingu ocorre, por exemplo, contrabando de mogno na terra indígena Kayapó (GUEDES, 2015).

Entre as consequências da expansão do agronegócio na região, estão a visível degradação ambiental e a ameaça aos territórios já conquistados pelos povos tradicionais. Mas o problema vai além, está intrinsecamente ligado ao modelo de desenvolvimento que o Estado brasileiro continua adotando para essa região desde a primeira metade dos anos 1970. Esse modelo foca em um desenvolvimento voltado para atender as necessidades do mercado, no qual os recursos naturais sofrem os mais diversos tipos de pressão e as diversidades étnicas e culturais são vistas como obstáculos à expansão dos lucros e ao aumento do saldo da balança comercial (KOHLHEPP, 2002; CARDOSO; MÜLLER, 2008).

Com a utilização da RCA (O’NEILL, 1982), os Cenários 3 e 4 (Figura 6) foram elaborados. Esses cenários partem da premissa de que os agropecuaristas possam vir a apropriar-se as áreas pertencentes às terras indígenas e unidades de conservação federais. Os cenários demonstram o potencial de degradação que pode ocorrer caso medidas efetivas de monitoramento e fiscalização não sejam tomadas. Destaca-se a redução das terras indígenas, de 
$53 \%$ para $26 \%$ da área total do município, acarretando uma degradação de áreas de preservação superior à $25.561 \mathrm{~km}^{2}$, além do avanço antrópico nas áreas de reserva legal, que pode chegar a $16.942,51 \mathrm{~km}^{2}(20 \%)$.

Figura 6 - Cenários simulando a apropriação das áreas protegidas pelos agricultores

\begin{tabular}{|c|c|c|c|c|c|c|}
\hline \multirow{2}{*}{$\begin{array}{l}\text { Classificação da } \\
\text { Área }\end{array}$} & \multicolumn{3}{|c|}{$\begin{array}{c}\text { Cenário } 3 \text { (Reinvidicação de Terras Indígenas pelos } \\
\text { Agricultores - GameTheory) }\end{array}$} & \multicolumn{3}{|c|}{$\begin{array}{c}\text { Cenário } 4 \text { (Reividicação de Todas as Áreas Protegidas } \\
\text { pelos Agricultores - GameTheory) }\end{array}$} \\
\hline & Descrição & Área $\left(\mathrm{km}^{2}\right)$ & Área (\%) & Descrição & Área $\left(\mathrm{km}^{2}\right)$ & Área (\%) \\
\hline TI: Terras Indígenas & $\begin{array}{l}\text { Substancialmente } \\
\text { Degradadas }\end{array}$ & 23438.26 & $27 \%$ & $\begin{array}{l}\text { Substancialmente } \\
\text { Degradadas }\end{array}$ & 22600.90 & $26 \%$ \\
\hline $\begin{array}{l}\text { UCs: Unidades de } \\
\text { Conservação Federais }\end{array}$ & $\begin{array}{l}\text { Parcialmente } \\
\text { Preservadas }\end{array}$ & 3349.41 & $4 \%$ & $\begin{array}{l}\text { Substancialmente } \\
\text { Degradadas }\end{array}$ & 2512.05 & $3 \%$ \\
\hline $\begin{array}{l}\text { CAR: Áreas de Cadastro } \\
\text { Ambiental Rural }\end{array}$ & Totalmente Utilizada & 54052.75 & $63 \%$ & Totalmente Utilizada & 55727.45 & $65 \%$ \\
\hline \begin{tabular}{|c|} 
ARL: Área de Reserva \\
Legal (Dentro das Áreas \\
de CAR)
\end{tabular} & $\begin{array}{l}\text { Parcialmente } \\
\text { Preservada }\end{array}$ & 22784.32 & $27 \%$ & $\begin{array}{l}\text { Parcialmente } \\
\text { Preservada }\end{array}$ & 23490.23 & $28 \%$ \\
\hline $\begin{array}{l}\text { AND: Áreas Protegidas } \\
\text { Degradadas }\end{array}$ & Forte Degradação & 23886.94 & $28 \%$ & Forte Degradação & 25561.66 & $30 \%$ \\
\hline $\begin{array}{c}\text { AR: Áreas } \\
\text { Remanescentes (Área } \\
\text { Total - TI - UCS - CAR) }\end{array}$ & Sem Alterações & 4473.82 & $5 \%$ & Sem Alterações & 4473.82 & $5 \%$ \\
\hline $\begin{array}{l}\text { AA: Área Agrícola } \\
\text { Irregular }\end{array}$ & $\begin{array}{l}\text { Áreas de Reserva Legal } \\
\text { com Produção Agrícola }\end{array}$ & 15973.63 & $19 \%$ & $\begin{array}{l}\text { Áreas de Reserva Legal } \\
\text { com Produção Agrícola }\end{array}$ & 16942.41 & $20 \%$ \\
\hline
\end{tabular}

Fonte: Elaboração própria.

As análises dos Cenários 3 e 4 podem ocorrer de forma integrada, uma vez que o Cenário 4 inclui, além das terras indígenas, toda a área das unidades de conservação federais entre as apropriações dos agropecuaristas. Entretanto, o aumento mais substancial das áreas agrícolas se dá a partir do avanço sobre as terras indígenas, uma vez que essas áreas possuem as maiores demarcações no município. Dessa forma, ao adotar equidade de poder entre os atores envolvidos, as simulações evidenciam que os povos indígenas carecem de ações de proteção, uma vez que seriam os grandes afetados na região a partir do avanço das fronteiras latifundiárias, fato já constatado no cenário atual.

Diante dos cenários apresentados, destaca-se ainda a incompatibilidade dos resultados com o Plano Diretor Municipal (Lei Municipal n 320/2006), onde o sudeste do município (região altamente degradada e com forte presença agropecuária) é classificado como macrozona de recuperação. Também nota-se que a área zoneada como macrozona de dinamização e uso produtivo invade a delimitação das terras indígenas em diversos locais.

Nessa mesma perspectiva, salienta-se que todas as propriedades de CAR pertencentes à área de Amazônia Legal devem possuir, segundo o Código Florestal (Lei n 12.651/2012), um percentual de $80 \%$ da área destinada a Reserva Legal. Entretanto, nas próprias demarcações 
atuais do governo (CAR, 2019), essa proporção já não é obedecida e demonstra as incongruências do Cadastro na região, onde o que deveria ser um instrumento de auxílio na regularização ambiental vem sendo utilizado, indevidamente, como um instrumento de regulamentação fundiária (TUPIASSU; GROS-DESORMAUX; DA CRUZ, 2017).

\section{CONSIDERAÇÕES FINAIS}

Esta pesquisa permitiu compreender a dinâmica dos conflitos pela posse de terras no município de São Félix do Xingu, no Pará, através da análise detalhada da relação do uso do recurso e dos usuários envolvidos, a partir dos estudos de Ostrom (1990; 2007). Quanto à presença dos princípios de Ostrom nos SG do município, constatou-se que a maioria dos princípios estão parcialmente presentes ou ausentes. De forma geral, a legislação vigente é bem definida, porém quando se analisa a aplicação destas, é ineficiente e a falta de fiscalização e monitoramento dificulta seu cumprimento.

Observou-se que o histórico de incentivos fiscais em políticas de expansão do agronegócio do município possui influência decisiva nas divergências entres os agropecuaristas e os povos indígenas, visto que o direito à propriedade não é bem definido e a legislação apresenta divergências que corroboram com a expansão ilegal da agropecuária nas áreas nativas protegidas. Os cenários propostos retratam a sobreposição de interesses privados e descumprimento de delimitações legais, ao simular o constante crescimento de reivindicações por parte dos latifundiários. Essa modelagem deve servir de alerta para autoridades legais na elaboração e efetividade de diretrizes que garantam a preservação ambiental e o direito do uso da terra pelos indígenas.

Para estudos futuros sugere-se: avaliar recortes espaciais menores dentro do limite municipal, levando em consideração relatos locais, capazes de explicar a dinâmica espacial das ações antrópicas na região; avaliar formas de espacializar as simulações realizadas, uma vez que as simulações atuais avaliam quantitativamente os impactos decorrentes das interações entre os atores na região a partir de dados de cobertura do solo.

\section{AGRADECIMENTOS}

Os autores agradecem a Coordenação de Aperfeiçoamento de Pessoal de Nível Superior (CAPES) e ao Conselho Nacional de Desenvolvimento Científico e Tecnológico (CNPq) pelas bolsas concedidas no âmbito do Programa de Pós-Graduação em Engenharia Civil e Ambiental da Universidade Federal de Campina Grande. 


\section{REFERÊNCIAS}

ALMEIDA, E. N. et al. O papel das instituições no êxito de programas de desenvolvimento rural sustentável na Amazônia Brasileira. Brazilian Journal of Development, Curitiba, v. 4, n. 6, p. 3417-3425, 2018.

AMARAL, S. et al. Redes e conectividades na estruturação da frente de ocupação do XinguIriri - Pará. Geografia, v. 31, n. 3, p. 655-675, 2006.

BECKER, B. K. Geopolítica da Amazônia. Estudos Avançados, São Paulo, v. 19, n. 53, p. 71-86, 2005. DOI 10.1590/s0103-40142005000100005.

BRASIL. Lei n. ${ }^{\circ}$ 9605, de 12 de fevereiro de 1998. Dispõe sobre as sanções penais e administrativas derivadas de condutas e atividades lesivas ao meio ambiente, e dá outras providências. Diário Oficial da União, Brasília, DF, n. 2, 13 fev. de 1998. Seção 1, p. 630.

Lei n ${ }^{\circ} 12.651$ de 25 de maio de 2012. Dispõe sobre a proteção da vegetação nativa. Diário Oficial da União, Brasília, DF, n. 1, 28 mai. de 2012. Seção 1, p. 1.

Lei $\mathrm{n}^{\circ} 10.257$ de 10 de julho de 2001. Regulamenta os arts. 182 e 183 da Constituição Federal, estabelece diretrizes gerais da política urbana e dá outras providências. Diário Oficial da União, Brasília, DF, n. 1, 11 jul. de 2001. Seção 1, p. 1.

Resolução $n^{\circ} 10$, de 17 de outubro de 2018. Dispõe sobre soluções garantidoras de direitos humanos e medidas preventivas em situações de conflitos fundiários coletivos rurais e urbanos. Diário Oficial da União, Brasília, DF, n. 1, 19 out. de 2018. Seção 1, p. 118.

CAMERER, C. F. Behavioral game theory: Experiments in strategic interaction. Princeton: Princeton University Press, 2011.

CANO-BERLANGA, S.; GIMÉNEZ-GÓMEZ, J.-M.; VILELLA, C. Enjoying cooperative games: The R package GameTheory. Applied Mathematics and Computation, v. 305, p. 381-393, 2017. DOI 10.1016/j.amc.2017.02.010.

CAR - Cadastro Ambiental Rural. Módulos de Cadastro, 2019. Disponível em: http://car.semas.pa.gov.br/\#/. Acesso em: 15 mar. 2020.

CARDOSO, F. H.; MÜLLER, G. Amazônia: expansão do capitalismo. Rio de Janeiro: Centro Edelstein de Pesquisas Sociais, 2008. Disponível em : https://static.scielo.org/scielobooks/mnx6g/pdf/cardoso-9788599662731.pdf. Acesso em: 5 mar. 2020.

CARNEIRO, M. S. A construção social do mercado de madeiras certificadas na Amazônia brasileira: a atuação das ONGs ambientalistas e das empresas pioneiras. Sociedade e Estado, Brasília, v. 22, n. 3, p. 681-713, 2007. DOI 10.1590/s0102-69922007000300008.

CHUN, Y.; LEE, J. On the convergence of the random arrival rule in large claims problems. International Journal of Game Theory, v. 36, n. 2, p. 259-273, 2007. DOI 10.1007/s00182007-0075-4. 
DINIZ, M. B.; OLIVEIRA JUNIOR, J. N. DE; TROMPIERI NETO, N.; DINIZ, M. J. T. Causas do desmatamento da Amazônia: uma aplicação do teste de causalidade de Granger acerca das principais fontes de desmatamento nos municípios da Amazônia Legal brasileira. Nova Economia, Belo Horizonte, v. 19, n. 1, p. 121-151, 2009. DOI 10.1590/s010363512009000100006.

EPSTEIN, I. The Babylonian Talmud. London: The Soncino Press, 1983.

ESCADA, M. I. S. et al. Processos de ocupação nas novas fronteiras da Amazônia: o interflúvio do Xingu/ Iriri. Estudos Avançados, São Paulo, v. 19, n. 54, p. 9-23, 2005.

FEISTAUER, D.; LOVATO, P. E.; SIMINSKI, A.; RESENDE, S. A. Impactos do Novo Código Florestal na regularização ambiental de propriedades rurais familiares. Ciência Florestal, v. 24, n. 3, p.749-757, 2014.

FONSECA-MORELLO, T. et al. Fires in Brazilian Amazon: why does policy have a limited impact? Ambiente \& Sociedade, São Paulo, v. 20, n. 4, p. 19-38, 2017.

FUNAI - Fundação Nacional do Índio. Terras Indígenas. Disponível em: http://www.funai.gov.br/index.php/indios-no-brasil/terras-indigenas. Acesso em: 5 mai. 2019.

GUEDES, M. H. Os desafios!. São Paulo: Clube dos autores, 2015.

HARDIN, G. The Tragedy of the Commons. Science, v. 162, n. 3859, p. 1243-1248, 1968.

HECK, E.; LOEBENS, F.; CARVALHO, P. D. Amazônia indígena: conquistas e desafios. Estudos Avançados, São Paulo, v. 19, n. 53, p. 237-255, 2005.

IBGE - Instituto Brasileiro de Geografia e Estatística. Base cartográfica: Grade estatística. 2016. Disponível em: ftp://geoftp.ibge.gov.br/recortes_para_fins_estatisticos/grade_estatistica. Acesso em: 20 jan. 2020.

Estimativas de população 2019. Disponível em: https://cidades.ibge.gov.br/brasil/pa/sao-felix-do-xingu/panorama. Acesso em: jan. 2020.

ICMBIO - Instituto Chico Mendes de Conservação da Biodiversidade. Unidades de Conservação, 2019. Disponível em: http://www.icmbio.gov.br/portal/unidadesdeconservacao/. Acesso em: 10 mai. 2019.

KOHLHEPP, G. Conflitos de interesse no ordenamento territorial da Amazônia brasileira. Estudos Avançados, São Paulo, v. 16, n. 45, p. 37-61, 2002.

LOUREIRO, V. R.; PINTO, J. N. A. A questão fundiária na Amazônia. Estudos Avançados, São Paulo, v. 19, n. 54, p. 77-98, 2005.

MAPBIOMAS. Mudança de cobertura e uso, 2017. Disponível em: http://plataforma.mapbiomas.org/map\#coverage. Acesso em: 10 mai. 2019.

MARENGO, J. A.; NOBRE, C.A.; CHOU, S. C.; TOMASELLA, J.; SAMPAIO, G.; ALVES, L. M. et al. Riscos das mudanças climáticas no Brasil: análise conjunta Brasil-Reino Unido 
sobre os impactos das mudanças climáticas e do desmatamento na Amazônia. São Paulo: INPE, 2011.

MARTINEZ, L. L.; FIEDLER, N. C.; LUCATELLI, G. J. Análise das relações entre desflorestamentos e focos de calor: estudo de caso nos municípios de Altamira e São Félix do Xingu, no Estado do Pará. Revista Árvore, Viçosa, v. 31, n. 4, p. 695-702, 2007.

MCGINNIS, M. D.; OSTROM, E. Social-ecological system framework: initial changes and continuing challenges. Ecology and Society, v. 19, n. 2, p. 30, 2014.

MORGENSTERN, O.; VON NEUMANN, J. Theory of games and economic behavior. Princeton: Princeton University Press, 1944.

MYERSON, R. B. Game theory. Cambridge: Harvard University Press, 2013.

OLSON, M. The Logic of Collective Action: Public Goods and the Theory of Groups, Second Printing with a New Preface and Appendix. Cambridge: Harvard University Press, 2009.

O'NEILL, Barry et al. A problem of rights arbitration from the Talmud. Mathematical social sciences, v. 2, n. 4, p. 345-371, 1982.

OSTROM, E. A diagnostic approach for going beyond panaceas. Proceedings of the National Academy of Sciences, v. 104, n. 39, p. 15181-15187, 2007.

A General Framework for Analyzing Sustainability of Social-Ecological Systems. Science, v. 325, n. 5939, p. 419-422, 2009.

Governing the commons: the evolution of institutions for collective action. Cambridge: Cambridge University Press, 1990.

PALHETA, J. M. et al. Conflicts over the use of territory in mineral Amazon. Mercator, v. 16, n. 10, p. 1-18, 2017.

PEREIRA, J. R.; CABRAL, E. H. S.; PEREIRA, J. R. Gestão Social e Governing the Commons: a Cooperação como Elo de Convergência. Revista de Ciências da Administração, v. 1, n. 1, p. 112, 2015.

RABINOVITCH, N. L. Probability and statistical inference in ancient and medieval Jewish literature. Toronto: University of Toronto Press, 1971.

REYDON, B. P. 13 Challenges of current land governance in Brazil. Agricultural Development in Brazil: The Rise of a Global Agro-food Power, p. 208, 2019.

REYDON, B. P.; FERNANDES, V. B.; TELLES, T. S. Land tenure in Brazil: the question of regulation and governance. Land use policy, v. 42, p. 509-516, 2015.

SAD - Sistema de Alerta de Desmatamento. Imazon. Sistema de Alerta de Desmatamento, 2019. Disponível em: https://imazon.org.br/wp-content/uploads/2019/12/SAD-Outubro2019.pdf. Acesso em: 01 mar. 2020. 
SÃO FÉLIX DO XINGU. Lei n ${ }^{\circ}$ 320, de 13 de outubro de 2006. Dispõe sobre o Plano Diretor de São Félix do Xingu. Prefeitura Municipal de São Félix do Xingu, São Félix do Xingu, PA, 13 out. 2006.

SCHMINK, M.; HOELLE, J.; GOMES, C. V. A.; THALER, G. M. From contested to 'green' frontiers in the Amazon? A long-term analysis of São Félix do Xingu, Brazil. The Journal of Peasant Studies, v. 46, n. 2, p. 377-399, 2019.

SCHMITT, Jair. Crime sem castigo: a efetividade da fiscalização ambiental para o controle do desmatamento ilegal na Amazônia. 2015. 188 f. Tese (Doutorado em Desenvolvimento Sustentável) - Universidade de Brasília, Brasília, 2015.

SCHULZ, C.; MARTIN-ORTEGA, J.; GLENK, K.; IORIS, A. A. R. The Value Base of Water Governance: A Multi-Disciplinary Perspective. Ecological Economics, v. 131, p. 241$249,2017$.

SEWARD, P.; XU, Y. The case for making more use of the Ostrom design principles in groundwater governance research: a South African perspective. Hydrogeology Journal, v. 27, n. 3, p. 1017-1030, 2019.

SHARMA, D. et al. A comparison of influences on the landscape of two social-ecological systems. Land Use Policy, v. 57, p. 499-513, 2016.

SILVA, C. A. F.; BAMPI, A. C. Regional Dynamics of the Brazilian Amazon: between Modernization and Land Conflicts. Cuadernos de Geografía: Revista Colombiana de Geografía, v. 28, n. 2, p. 340-356, 2019.

SILVA, F. de F.; FULGINITI, L. E.; PERRIN, R. K. The Cost of Forest Preservation in the Brazilian Amazon: The "Arc of Deforestation". Journal of Agricultural and Resource Economics, Lincoln, v. 44, n. 3, p. 497-512, 2019. DOI 10.22004/ag.econ.292328

SMITH, J. M. Evolution and the Theory of Games. Cambridge: Cambridge University Press, 1982.

SOARES-FILHO, B. S.; NEPSTAD, D. C.; CURRAN, L.; CERQUEIRA, G. C.; GARCIA, R. A.; RAMOS, C. A. et al. Cenários de desmatamento para a Amazônia. Estudos Avançados, São Paulo, v. 19, n. 54, p. 137-152, 2005.

SOUZA, C.; AZEVEDO, T. MapBiomas General Handbook. São Paulo: MapBiomas, 2017.

SPAROVEK, G.; REYDON, B. P.; GUEDES PINTO, L. F.; et al. Who owns Brazilian lands? Land Use Policy, v. 87, p. 104062, 2019.

TEAM, RCORE. R: A language and environment for statistical computing. Boston: RStudio Inc., 2013.

TORTAJADA, C. Water Governance: Some Critical Issues. International Journal of Water Resources Development, v. 26, n. 2, p. 297-307, 2010. 
TOTTI, M.; AZEVEDO, S. Gestão de Recursos Naturais de uso Comum: Peculiaridades e Abordagens Teóricas. Revista Brasileira de Recursos Hídricos, v. 18, n. 3, p. 41-51, 2013.

TUPIASSU, L.; GROS-DESORMAUX, J.; DA CRUZ, G. A. C. Regularização fundiária e política ambiental: incongruências do cadastro ambiental rural no estado do Pará. Revista Brasileira de Políticas Públicas, v. 7, n. 2, p. 189-203, 2017.

WAMSLER, C.; RAGGERS, S. Principles for supporting city-citizen commoning for climate adaptation: From adaptation governance to sustainable transformation. Environmental Science \& Policy, v. 85, p. 81-89, 2018.

WANG, Y.; ZHANG, M.; KANG, J. How does context affect self-governance? Examining Ostrom's design principles in China. International Journal of the Commons, v. 13, n. 1, p. 660, 2019.

WITTMAN, H. et al. A social-ecological perspective on harmonizing food security and biodiversity conservation. Regional Environmental Change, v. 17, n. 5, p. 1291-1301, 2017.

YI, H.; FEIOCK, R. C. Renewable Energy Politics: Policy Typologies, Policy Tools, and State Deployment of Renewables. Policy Studies Journal, v. 42, n. 3, p. 391-415, 2014. 